\title{
General Psychiatry An evolutionary life history approach to understanding mental health
}

To cite: Han W, Chen B-B. An evolutionary life history approach to understanding mental health. General Psychiatry 2020;33:e100113. doi:10.1136/ gpsych-2019-100113

Received 21 November 2019 Revised 05 July 2020 Accepted 20 July 2020

\section{Check for updates}

(C) Author(s) (or their employer(s)) 2020. Re-use permitted under CC BY-NC. No commercial re-use. See rights and permissions. Published by BMJ.

Department of Psychology, Fudan University, Shanghai, China

Correspondence to Dr Bin-Bin Chen; chenbinbin@fudan.edu.cn

\section{ABSTRACT}

In recent years, evolutionary life history theory has been used as a heuristic framework to understand mental health. This article reviews the life history theory and its integration with mental disorders and then introduces representative research methods and related empirical studies in the field of evolutionary psychopathology. In the end, this article concludes with future directions for further research examining and developing the evolutionary psychopathological framework.

Evolutionary psychology has been applied in many subfields of psychology and accumulated expanding empirical evidence, such as developmental psychology, economic psychology, personality psychology and psychopathology. In recent years, Del Giudice ${ }^{1-3}$ proposed that the life history theory, a branch of evolutionary theory, could well explain the symptoms of psychopathology in terms of individual difference in ecological, biological and psychological factors. In this article, we first reviewed the life history theory framework, and how it integrated with psychopathology research by analysing several mental disorders in this perspective. Next, we introduced some representative research methods and related empirical studies in the field of evolutionary psychopathology. Last, we concluded and discussed some future directions within an evolutionary psychopathological framework.

\section{THEORETICAL FRAMEWORK}

In evolutionary psychology, successful replication of genes is the ultimate aim of an organism, so all traits and behaviours serve for reproductive fitness. For an organism, geting reproductive fitness is defined as 'adaptive', conversely, defined as 'maladaptive'. However, in psychiatry, 'adaptive' refers to the function of behaviours and traits that benefit health, well-being and social life. Regardless of the essential goals for happiness or health, natural selection shapes an organism's mental and physical mechanisms in response to different ecological conditions to maximise reproductive success. ${ }^{5}$ Some behaviours and traits have been adaptive during evolution. However, with the development of social norms, these manifestations may be considered undesirable in terms of mental health and can be defined as psychopathological symptoms, which can also be referred to as pseudopathologies. ${ }^{6}$ For this reason, some evolutionary literature replaces 'adaptive' as 'desirable' to differentiate evolutionary adaptiveness from biological adaptiveness. ${ }^{1}$ This provides an overview of how evolutionary life history theory explains mental health: natural selection favours exclusive reproductive fitness.

\section{Life history theory}

Life history theory, one of the most influential evolutionary theories, describes a comprehensive framework to explain how organisms allocate limited resources to competing developmental tasks over the life span to maximise evolutionary fitness. ${ }^{7-10}$ According to life history theory, these tasks can be classified into somatic effort and reproductive effort, which contribute to future and current reproductive success, respectively. Somatic effort refers to growth, survival and maintenance of one's body and mind, including the acquirement of skills, knowledge, strength and other embodied capital, providing the foundation for the development and reproduction in the future. ${ }^{811}$ The reproductive effort consists of mating effort and parental effort and aims to get immediate reproduction opportunities and improve the quality of offspring, respectively. ${ }^{7}$ The trade-off also involves allocation between less offsprings with high investment in each one and more offsprings with less investment. Therefore, it can be defined as trade-offs between offspring quality and quantity. ${ }^{7}$ Facing this trade-off, if an organism invests more in somatic effort, it will put fewer resources in reproductive effort, and vice versa.

The way individuals allocate energy contributes to the variability of life history strategies, which lies on a slow-to-fast continuum. ${ }^{12}$ Different life history strategies 
Table 1 Life-history-strategy-related behaviours and traits

Fast life history strategy

Slow life history strategy

\begin{tabular}{|lll}
\hline $\begin{array}{l}\text { Physiological outcomes } \\
\text { Rate of development }\end{array}$ & Faster & Slower \\
\hline $\begin{array}{l}\text { Onset of puberty } \\
\text { Life expectancy }\end{array}$ & Earlier & Later \\
\hline $\begin{array}{l}\text { Mating } \\
\text { Sexual maturation }\end{array}$ & Shorter & Longer \\
\hline Sexual partners & Earlier & Later \\
\hline Relationship oriented & More & Fewer \\
\hline Parenting & Casual & Committed \\
\hline Age of reproduction & Earlier & \\
\hline Number of offspring & Higher & Later \\
\hline Parental investment & Lower & Smaller \\
\hline Psychological traits & Higher \\
\hline Attachment & Insecure and unstable & \\
\hline Reward orientation & Short and immediate & Secure and stable \\
\hline Prosocial tendencies & Lower cooperation, antisocial & Long and delayed \\
\hline Impulsivity & High, risk-taking, sensation-seeking & Higher cooperation, prosocial \\
\hline Personality & Low conscientiousness and agreeableness & Low, risk-avoidance, stick to routines \\
\hline Ecological conditions & & \\
\hline Predictability & Unpredictable & Predictable \\
\hline Harshness & Harsh & Affluent \\
\hline
\end{tabular}

It was adapted from Baumard's work. ${ }^{13}$

vary in physiological, reproductive choice and psychological outcomes (table 1). ${ }^{13}{ }^{14}$ Faster strategists are prone to allocate more time and energy to reproductive effort and prioritise short-term returns over long-term ones. Conversely, slower strategists, are liable to focus more on somatic effort and prioritise fitness rewards later. $^{915}$

At the physiological level, fast life history strategies are associated with a higher rate of development and earlier maturation. In contrast, slow life history strategies are related to later and slower physiological development. ${ }^{716}$ As for reproductive choice, fast strategists have more sexual partners and more casual relationships, give birth earlier, have more children and invest less in each child. Slow strategists are more likely to have devoted and committed romantic relationships and have fewer children in whom they invest more. ${ }^{10}{ }^{17}$ Concerning psychological outcomes, slower strategies are associated with far-sighted behaviours including risk avoidance, optimism and cooperation; on the contrary, faster strategies are associated with short-sighted behaviours, such as impulsiveness, risk-taking and aggression. ${ }^{18-22}$ In short, the two strategies are about choices between current and future reproduction, and quality and quantity of offspring, both of which cause different clusters of life history strategy traits. ${ }^{1} 78$
Role of environmental conditions on life history strategy

Individuals' life history strategies are influenced by ecological conditions, which are characterised by harshness (high mortality and morbidity) and unpredictability (e.g., high-level variation of mortality). ${ }^{70}$ The environment with a high level of harshness and unpredictability prompts individuals to adopt faster life history strategies. ${ }^{1} 1017$ Under this environmental condition, individuals have a shorter life expectancy and they make use of all their energy to attract mates to reproduce more children, rather than investing in somatic effort that has lower immediate benefits. In contrast, individuals who live in a favourable and stable environment have a longer life span and are more likely to develop slow life history strategies. They have affluent resources to invest in somatic effort and prepare for later reproduction. ${ }^{7811} 17$ Life history theory emphasises that the early environment in the first 5-7 years of life plays a critical role in the development of life history strategies. ${ }^{71023}$ Individuals develop life history strategies in this sensitive period and vary in developmental trajectories and future trade-offs. Studies have found that the life history strategies in adulthood are associated with the childhood environment rather than the adult environment. ${ }^{2024}$

In empirical studies, early environmental harshness is often measured by socioeconomic status (SES). 
Furthermore, exposures to violence, neighbourhood hazards, and harsh parenting are also cues of high mortality and morbidity associated with fast life history strategies. ${ }^{7}$ The indicators of environmental unpredictability involve parental transitions (e.g., divorce, death and remarriage ${ }^{25}$ and residential changes, ${ }^{7}$ which foretell fast life history strategies.

Furthermore, individuals' life history strategies are jointly influenced by genetic and ecological conditions. ${ }^{10} 26-28$ For example, the differential susceptibility model suggests that, facing the same environmental conditions, individuals with different susceptibility may have different developmental trajectories. ${ }^{29}$

\section{Life history strategy and mental health}

Del Giudice ${ }^{1}$ proposed that adaptive features-lifehistory-related traits and life history strategies-in some ways could become a cause of social-undesirable symptoms through three causal pathways. First, life-historyrelated traits are double-edged swords: even a strategy can be adaptive in terms of evolutionary fitness, it may be regarded as undesirable symptoms and increase vulnerability to dysfunction (e.g., more likely to be exposed to environmental risk factors), and cause physiological and psychological health problems. Second, life-historyrelated straits may express beyond the average level of adaptive features and results in maladaptiveness. Third, some adaptive strategies are beneficial to the fitness of all organisms on average, but impose high costs, for example, causing mental disorders in a harsh and unpredictable environment for some individuals. Meanwhile, these pathways may exist alone or coexist in one disorder.

Recently, there has been overwhelming literature that has examined the relationship between mental disorders and life-history-related traits. Del Giudice ${ }^{1-3}$ systematically reviewed the existing empirical evidence and categorised related disorders into fast or slow spectrum pathology based on life history theory (see table 2 ). The fast spectrum disorders included attention-deficit/hyperactivity disorder (ADHD), autogenous obsessive-compulsive disorder, borderline personality disorders (BPDs), disruptive, impulse-control and conduct disorders (DICDs), eating disorders (EDs) (dysregulated profile), alcohol use disorders (type 2) and schizophrenia spectrum disorders (SSDs).
In contrast, autism spectrum disorders (ASDs), depression, EDs (perfectionist and overcontrolled profiles), obsessivecompulsive personality disorder (OCPD), reactive obsessive-compulsive disorders and alcohol use disorders (type 1) were classified into slow spectrum disorders. In the next subsections, we summarised recent related literature about these mental disorders. The evidence is organised according to table 1 from the perspective of fast and slow life history strategies based on Del Giudice's work. ${ }^{12}$

\section{Attention-deficit/hyperactivity disorder}

ADHD is a neurodevelopmental disorder characterised by inattentive, hyperactive and impulsive behaviours in Diagnostic and Statistical Manual of Mental Disorders (DSM5), with impairments in social interaction, occupational and educational performance. ${ }^{30}$

There is some evidence showing that ADHD is a kind of fast spectrum disorder. For example, ADHD is correlated with high impulsivity and aggression, ${ }^{31}$ low consciousness and agreeableness, ${ }^{32}$ unrestricted sexuality, ${ }^{33}$ and low SES. ${ }^{34}$ Besides, ADHD has high comorbidity with schizophrenia and externalising disorders. ${ }^{2}$ However, ADHD may be heterogeneous and have different subtypes; for instance, some ADHD cases show less aggression or higher consciousness. ${ }^{35}$ It is necessary to explore different subtypes of ADHD.

\section{Obsessive-compulsive spectrum}

Obsessive-compulsive (OC) spectrum disorders are characterised by recurring, intrusive and uncontrolled thoughts, and ritualistic behaviour in DSM- $5 .{ }^{30}$ OC spectrum disorders are classified into two subtypes: autogenous obsessions and reactive obsessions. Autogenous obsessions are related to unidentifiable, abrupt and internal thoughts, whereas reactive obsessions are associated with identifiable external stimuli, such as fears of failure, accidents or asymmetry. ${ }^{36}$ Autogenous obsessive-compulsive spectrum is associated with fast life history strategies, ${ }^{1}$ such as low inhibition ${ }^{37}$ reactive obsessive-compulsive spectrum can be categorised into the slow spectrum, ${ }^{1}$ which show high inhibitory control. ${ }^{37}$

Table 2 Life history taxonomy of some mental health disorders

\begin{tabular}{ll}
\hline Fast spectrum disorders & Slow spectrum disorders \\
\hline Attention-deficit/hyperactivity disorder (heterogeneous) & Autism spectrum (heterogeneous) \\
Autogenous obsessive-compulsive disorder & Depression (heterogeneous) \\
Borderline personality disorder & Eating disorders (perfectionist and overcontrolled profiles) \\
Eating disorders (dysregulated profile) & Reactive obsessive-compulsive disorder \\
Disruptive, impulse-control and conduct disorders & Obsessive-compulsive personality disorder \\
Schizophrenia spectrum & Alcohol use disorders (type 1) \\
Alcohol use disorders (type 2) & \\
\hline
\end{tabular}

It was edited based on the works by Del Giudice. ${ }^{1-3}$ 


\section{Borderline personality disorder}

BPD is characterised by difficulties in emotion regulation, fear of being abandoned, high impulsivity and risktaking, and unstable interpersonal relationships. ${ }^{30}$ Some evidence indicates that BPD reflects a fast life history strategy: less parental investment and higher mating effort, more risky sexual behaviours and adverse childhood environment. ${ }^{38-40}$

\section{Disruptive, impulse-control and conduct disorders}

DICDs include oppositional defiant disorder, conduct disorder, intermittent explosive disorder and other related disorders in DSM-5. ${ }^{30}$ DICDs have been classified as a representative of fast spectrum psychopathology by many pieces of literature. DICD symptoms are associated with fast life history strategies, such as impulsive behaviour, substance abuse, antisocial behaviour, ${ }^{41}$ early sexual debut, ${ }^{42}$ more problematic sexual behaviours ${ }^{43}$ and early maturation. ${ }^{44}$ As for personality, DICDs are associated with low agreeableness, low conscientiousness and high neuroticism. ${ }^{45}$ And DICDs are more prevalent in unpredictable and harsh family environments, for example, more negative life event, low family SES and low paternal mental health. ${ }^{46-48}$ These highly risky and exploitive strategies of DICDs increase the likelihood of surviving in a harsh environment, which causes adaptive but undesirable outcomes. ${ }^{1}$

\section{Eating disorders}

Eating disorders (EDs) are a family of disorders characterised by excessive concern with weight and abnormal eating habits. ${ }^{30}$ EDs are classified into three subtypes according to personality heterogeneity: dysregulated, perfectionist and overcontrolled profiles. ${ }^{49}$ Del Giudice classified three subtypes into fast or slow spectrum disorders: the dysregulated subtype characterised by impulsivity, insecure attachment and emotion dysregulation, reflecting fast life history strategies; the perfectionist subtype characterised by high consciousness and negative affectivity, reflecting slow life history strategies; the overcontrolled subtype characterised by interpersonal avoidance, low self-esteem and constricted emotionality, reflecting slow life history strategies. ${ }^{1}$ There needs to be further empirical evidence to confirm this classification.

\section{Schizophrenia spectrum disorders}

SSDs are characterised by delusions, hallucinations, disorganised thinking and disorganised behaviours. ${ }^{30}$

Why SSDs are harmful to survival and reproductive success but remain at approximately $1 \%$ morbidity and high heritability ${ }^{50}$ is puzzling. ${ }^{51}$ The sexual selection mode $^{5152}$ hypothesises that high level of verbal/artistic creativity, one of core schizotypal traits, ${ }^{53-55}$ is a fitness indicator that contributes to mating success rather than survival success. It is like the gorgeous but cumbersome peacock tail, a kind of morphological feature indicating the high quality of genes and promising reproductive success. ${ }^{1}$ Schizotypy is sensitive to genetic quality and ecological conditions. It can be an adaptive trait to promote mating success when genetic fitness is functional (e.g., high harmful genetic mutations) and developmental ecological conditions are favourable (e.g., high parental investment). ${ }^{51}$ However, if the contrary happens, it goes to another maladaptive and dysfunctional extreme: schizophrenia impairs courtship success. So Shaner and colleagues ${ }^{51}$ depicted schizophrenia as 'the unattractive, low-fitness extreme of a highly variable mental trait that evolved as a fitness indicator through mutual mate choice'.

In this sense, schizophrenia is corresponding to the third pathway of life history strategy to psychopathology proposed by Del Giudice, ${ }^{1}$ which indicates a fast life history oriented towards short-term mating success. ${ }^{53} 56$ Recent mounting research validates this hypothesis; for example, schizophrenia is associated with more sexual partners $^{57}$ and lower investment in long-term close relationships. ${ }^{58}$ Besides, a high level of schizotypal traits is linked to higher aggressivenes $\mathrm{s}^{59}$ and lower agreeableness. Evidence shows that the harsh environment increases the risk of SSDs,${ }^{606}$ coinciding with the fast life history strategists. ${ }^{57}$ In a nutshell, SSDs represent a kind of extreme fast life history strategies to maximise the chance of reproduction successfully with the cost of health.

\section{Substance use disorders}

Substance use disorders refer to the harmful or illegal use of drugs, including alcohol, cocaine, hallucinogens and other drugs. ${ }^{30}$ For alcohol use disorders, the two subtypes of substance abuse, type 1 and type 2, are associated with slow and fast life history strategies, respectively. ${ }^{62}$ Type 1 shows low impulsivity, risk-avoidance, high reward dependence and high family SES, whereas, type 2 reflects fast spectrum psychopathology, such as sensation seeking, low risk-avoidance and low reward dependence. ${ }^{2} 6263$

\section{Autism spectrum disorders}

The ASDs are a set of highly heritable disorders characterised by social interaction impairment, communication impairment, and repetitive behaviours and interests. ${ }^{30}$ Some studies propose that autistic-like traits and schizotypal traits are two poles of slow-fast life history strategies continuum, respectively. ${ }^{53}{ }^{56}$ Autistic-like traits are associated with less risky behaviour and sensation seeking, ${ }^{56} 64$ lower sex drive, ${ }^{65}$ less mating effort and more long-term investment, ${ }^{53}$ and later sexual maturation in women. ${ }^{66}$ Moreover, older parents increase the risk for autism. ${ }^{67}$ However, for personality, some studies find that autism symptom severity is negatively related to agreeableness and conscientiousness; ${ }^{68}{ }^{69}$ ASDs and ADHD have high comorbidity. ${ }^{70}$ The present controversial evidence indicates that ASDs may comprise different subtypes in the perspective of life history theory. ${ }^{2}$

\section{Depression}

Depression is characterised by a long-time low mood and low interest. ${ }^{30}$ There is empirical evidence showing 
that depression reflects fast life history strategies: low agreeableness, conscientiousness and disinhibition, high aggression and impulsivity and low SES; $;^{71-74}$ early puberty and sexual experience are risk factors for depression. ${ }^{75}$ However, some studies imply that depression is heterogeneous and show slow-spectrum characteristics (e.g., secure attachment). ${ }^{76}$

\section{Obsessive-compulsive personality disorder}

OCPD is characterised by extreme concerns with orderliness or neatness, perfectionism, excessive need for mental and interpersonal control, and rigid adherence to rituals. ${ }^{30}$ OCPD is categorised into a kind of slow spectrum disorder: it is correlated with risk and harm avoidance, delayed gratification, discounting of immediate rewards, behavioural inhibitory, conscientiousness, high SES and high parental effort. ${ }^{77}$

Table 2 does not include all kinds of mental disorders that are mentioned in DSM-5, and there is still much to be done to optimise the theoretical framework.

There are some limitations of traditional psychopathological taxonomy. In psychopathology research, the internalising-externalising category used by DSM-5 is one of representative taxonomies. ${ }^{78}$ The dimensional approach has been proved to have limited reliability in explaining two key phenomena: ${ }^{38} 79$ (1) The comorbidity between different disorders, for example, OCD (obsessive-compulsive disorder) is classified into internalising spectrum but positively associated with externalising problems. ${ }^{80}$ (2) The heterogeneity of the same disorder, for example, OCDs have different subtypes. ${ }^{1}$ But the life history theory framework makes it easy to understand the high co-occurrence and heterogeneity of some disorders. Different subtypes reflect different life history strategies in response to specific environmental conditions.

Many empirical studies indicate that ' $p$ factor', a general factor of psychopathology, is above internalising, externalising and psychotic domains. ${ }^{81-83}$ Studies show that scores on $p$ are positively associated with the biological dysfunction, difficult early developmental conditions, serve adult life impairment and family history of mental disorders. ${ }^{83}$ The $p$ factor represents a genetic and biological susceptibility factor to environmental risks (e.g., trauma exposure $)^{383}$ and corresponds to the genetic factors and early environmental risk factors in the framework of life history theory. ${ }^{1}$ In this sense, the hierarchical taxonomy of psychopathology provides robust empirical evidence to testify the validity of life history theory approach. However, the life history theory framework draws a more detailed, systematic and comprehensive blueprint for psychopathological studies, which constructs a pathway form the ecological and biological foundation to morphological, physiological and psychological symptoms of disorders.

\section{RESEARCH METHOD}

There is substantial work evaluating the relationship between mental health disorders and life history strategies with various research methods, for instance, cross-sectional, longitudinal and experimental designs. There are three aims of related studies: (1) To demonstrate the correlation of life history related traits (e.g., personality, sexual maturation, impulsivity and rate of development) and psychopathology; (2) To indicate the risk and protective factors of disorders; (3) To explore the underlying mechanism based on life history theory.

\section{CROSS-SECTIONAL DESIGN}

In medical research, a cross-sectional study is a kind of observable research method used to collect data from one or different groups at the same specific time point, which depicts the distribution and morbidity of a specific disease and the link of diseases and ecological factors. The primary statistical analysis methods include correlation analysis, structural equation modelling (SEM) and regression analysis, to reveal the phenomenological correlation.

Cross-sectional studies accumulate a great deal of direct and indirect evidence for evolutionary psychopathology. For instance, Hurst and Kavanagh ${ }^{4}$ measured participants' life history strategies using Mini-K and High-K Strategy Scale, which assessed behavioural traits and personality traits, respectively. This study also measured the intensity and frequency of several mental health symptoms included in DSM-5. After controlling age, the results showed a significant positive correlation between fast life history strategies scores and total psychopathology.

Although cross-sectional studies could provide enlightening evidence for the correlation of psychopathology and life history theory, in most cases, they could not determine temporal or causal relation and the direction of the causal relation.

\section{LONGITUDINAL DESIGN}

Longitudinal research is based on the design that observes the same group to collect the same cluster of variables at multiple time points, which can last for 1 year to several decades. Contrary to the cross-sectional design, the longitudinal study can trace the variables' orbits of change and provides a possibility to determine the exact causal nature of mental disorders based on time series. Using a sequence mediation model, a kind of SEM, these studies aim to uncover how life history strategy influences psychopathology symptoms.

A recent 6-year longitudinal study with a sample of 1245 adolescents and their parents from nine countries found that externalising problems were associated with fast life history strategies. ${ }^{84}$ Chang and collaborators measured environmental harshness and unpredictability in 10-year olds, life history strategies (self-control, parent-child relationship, family support, social support and general altruism) in 13-year olds, and externalising behaviours using Child Behaviour Checklist reported by parents and children in 15-year olds. The SEM results indicated that early harsh and unpredictable environment had an 
impact on adolescent externalising behaviours, which was mediated by life history strategy. The unfavourable childhood environment fostered the fast life history strategy of children, and then fast life history strategies, in turn, regulated children's behaviours and development.

It is still in question of how early environmental conditions affect behaviours, personality, mating and other related life domains. For example, some studies have found that harsh and unpredictable neighbourhood and parenting environments in childhood predict earlier age of sexual maturation and then cause greater sexual risk-taking behaviours and delinquency in adolescents. ${ }^{85}$ However, other studies using the sequence equation modelling found that personality mediated the association between early environment and adulthood life outcomes. ${ }^{4}$ More prospective or retrospective longitudinal design over the life span is necessary to find mediating and moderating variables.

\section{EXPERIMENTAL DESIGN}

The experimental design is to establish a causal relationship between different variables. In psychopathological research, this method is usually applied in drug and treatment efficiency study, brain function and structure study, and other cognitive function or performance study (e.g., visual attention and problem-solving).

Griskevicius and colleagues first adopted the experimental paradigm in the framework of life history theory. They employed experimental priming methods (e.g., reading materials about the present increasing mortality and unsafety) and conducted a series of experiments to test life history theory related behavioural tendency (e.g., risk-taking, delay reward and reproductive choice in women). ${ }^{20} 2186$ This work yields insight into combined action of current environmental clues and early childhood environment. The series empirical studies demonstrate that when encountering unsafe environmental clues (e.g., mortality threat, resource scarcity and economic recession priming), individuals who grew up in unfavourable childhood environments have short-term reward orientation (e.g., impulsivity, priority to mate and intention to have more children). Conversely, those who grew up in favourable conditions maintain long-term reward orientation.

Few studies have examined different mental disorders using experimental manipulation. Intriguingly, Brüne ${ }^{39}$ adopted Griskevicius' priming procedure in participants with BPD. Participants with BPD and the control group were instructed to imagine themselves in three romantic relationship conditions: 'predictably safe', 'unpredictably safe-risky' and 'predictably risky', which were based on the level of resource availability, and then fill in the Birkbeck Mating Questionnaire about their mating and reproduction choice after priming different ecological clues. The result showed that patients with BPD were significantly more likely to engage in sexual affairs early than the control group, and even in the predictably safe
Cultural and Historical Context

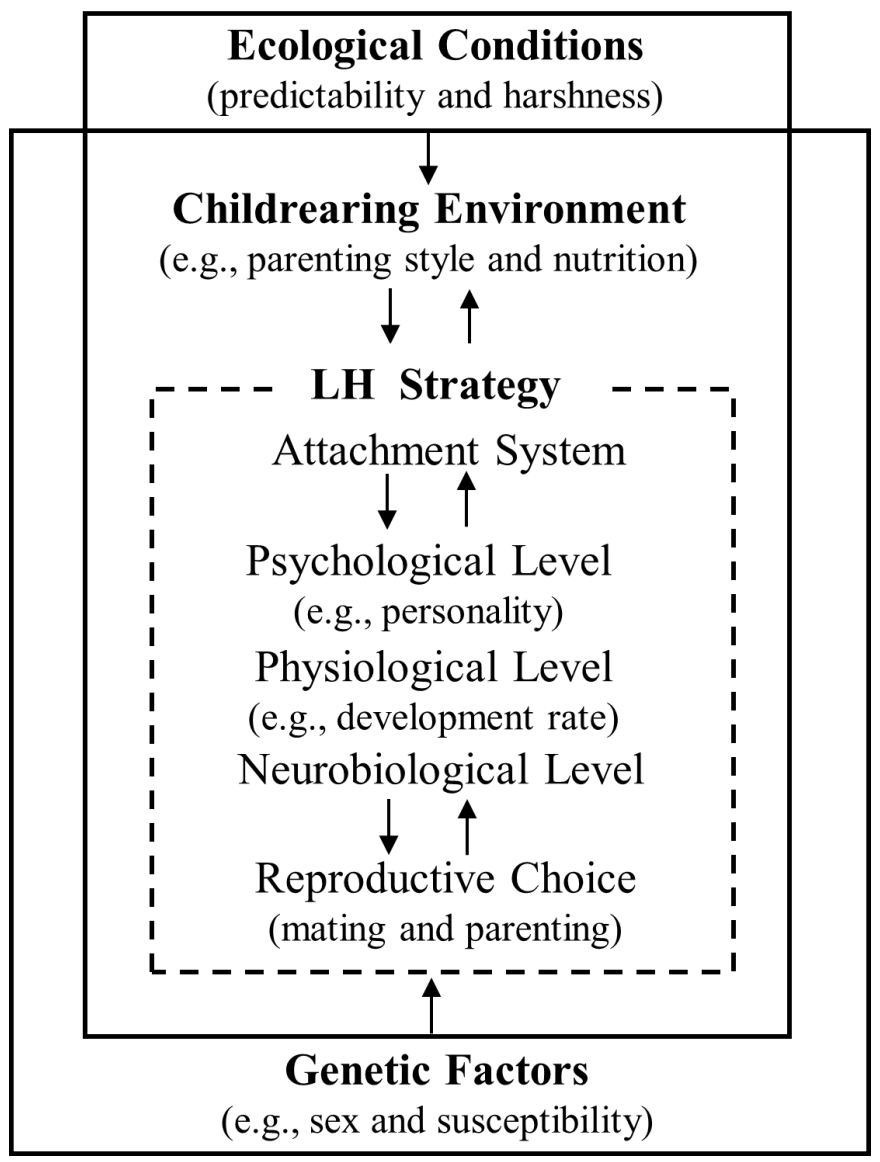

Figure 1 An integrated model of psychopathology in evolutionary life history theoretical framework. LH, Life history

condition, they expected less parental investment from their hypothetical partners. This study verifies that BPD is a kind of fast spectrum disorder.

In addition to these research designs listed above, there are other study methods. For example, Del Giudice ${ }^{87}$ used a simulation study, a kind of computer experiment, to create data based on hypotheses and use mathematical models to test the integrating degree between psychopathological symptoms and life history strategies.

\section{FUTURE DIRECTION}

Based on the existing literature, we present an integrated model of psychopathology in an evolutionary life history theoretical framework (see figure 1). The outermost layer of this model is the cultural and historical context. For example, monogamous culture and polygamous culture have different attitudes to sociosexuality. ${ }^{8}$ Ecological conditions and genetic factors embedded in the macro background jointly affect individuals' development. Ecological conditions shape the child-rearing environment (e.g., parenting style and nutrition), which influences individuals' life history strategies, including psychological, physiological, neurobiological outcomes and reproductive choice with the attachment system as 
the centre. In this model, genetic factors embrace sex, susceptibility and mutation load. Sex difference is an essential topic in evolutionary psychopathology because sexual asymmetries introduced by sexual selection causes differences in life history strategies and psychopathology. ${ }^{1}$ Note, arrows in the figure do not necessarily mean causal relationships, because every part of the model can interplay and shape other life domains. This model may be useful for future research. Some points should be emphasised

First, in recent years, some promising theories and models have been proposed to explain the structure of psychiatric disorders. Attachment theory is one of the representative theories that has been considered a fruitful framework for the origins and treatment of mental disorders. Mounting literature proposes that insecure attachment is a critical factor of understating mental health. ${ }^{89-91}$ From the perspective of attachment theory, insecure, unreliable and inconsistent attachment contributes to vulnerability to life stress and adversity, and many mental disorders are associated with insecure attachment. ${ }^{91}$ Moreover, boosting secure attachment is effective in releasing the symptoms. ${ }^{91}$ Attachment is regarded as a mediator to link environmental conditions and developmental outcomes in the life history theory. The early environmental clues shape the childrearing environment (parenting style) that is a direct signal of the present ecological risk and uncertainty for children and makes the foundation for their attachment. Children discern different environmental clues and develop secure or insecure attachment corresponding to different developmental trajectories: slow and fast life history strategies. ${ }^{10} 92-94$ It is necessary to include attachment as a core and conjunctive indicator of different mental health conditions from the perspective of life history theory to offer an integrative framework to develop effective therapies.

Second, life history theory manifests environmental and genetic factors; both have impacts on shaping an individual's life history strategy. ${ }^{26}$ The interaction of gene and environment $(\mathrm{G} \times \mathrm{E}$ interaction) plays a crucial role in behavioural, psychological and physiological developmental outcomes. Different individuals have different developmental plasticity. For example, some individuals are more susceptible to both adverse and favourable ecological conditions than others. ${ }^{29} 95$ Many disorders are moderate to highly heritable, ${ }^{1}$ so it is important to reveal how genes interact with the early environment. The next essential step to extend the framework is to integrate current research findings focusing on behavioural and personality traits, with neurobiological, imaging and genetic outcomes from life history theory. ${ }^{1339}$

Third, some scholars hypothesised that different rates and degrees of brain development, as well as adrenal and gonadal development, could contribute to individual differences in life history strategies. ${ }^{12}$ There is still little empirical neurological and biological evidence for psychopathology to test this hypothesis. However, the early life stress (ELS) theory provides an insight into this integration, indicating that early adverse environments, including maternal depression, abuse, maltreatment and neglect, have a long-term negative effect on brain function and neuroendocrine responsiveness and then increase the risk of psychopathology. Future investigations of ELS help integrate life history theory with the neurobiological and neuroendocrine change of psychopathology. For example, many pieces of research show that ELS causes damage to the hypothalamic-pituitary-adrenal axis regulation and impairs brain regions' function related to regulation of emotion, which may increase the possibility of depression. ${ }^{96}$ Furthermore, some animal studies indicate that ELS and present stressful life events both have effects on the dysregulation of serotonergic systems in some stress-related neuropsychiatric disorders. ${ }^{97}$ For instance, ELS exposure is correlated with 5-hydroxytryptamine deficiency and depression. ${ }^{98} 99$ Because of the lack of clinical empirical studies, there is less direct evidence about the relationship between life history strategies, neurological changes and psychopathology. It is necessary to conduct longitudinal studies to explore the mechanism in the future.

In addition to attachment and gene, direct and indirect studies in terms of psychopathology in the approach of life history helps validate and extend the present framework. Many disorders are still in an ambiguous classification (e.g., post-traumatic stress disorder and sleep arousal disorder). Brüne ${ }^{39}$ proposed that most of disorders may be a mixture of fast and slow spectrum rather than single polar spectrum. Maybe, the fast-slow spectrum will be a coordinate axis: every disorder has a coordinate that shows the extent of fast and slow life-history-strategy-related traits, rather than simple classification.

In summary, future studies are expected to apply multidisciplinary and multidimensional study methods (e.g., cross-cultural study) to depict a comprehensive evolutionary taxonomy and treatment system of mental disorder.

Contributors BBC developed the structure of the manuscript and wrote this manuscript together with WH.

Funding This study is supported by the Fudan University's 'Double First Class' initiative key project 'Sociological Theory and Method Innovation Platform for Social Transformation and Governance' and the research fund of the School of Social Development and Public Policy at Fudan University.

Competing interests None declared.

Patient consent for publication Not required.

Provenance and peer review Commissioned; externally peer reviewed.

Open access This is an open access article distributed in accordance with the Creative Commons Attribution Non Commercial (CC BY-NC 4.0) license, which permits others to distribute, remix, adapt, build upon this work noncommercially, and license their derivative works on different terms, provided the original work is properly cited, appropriate credit is given, any changes made indicated, and the use is non-commercial. See: http://creativecommons.org/ licenses/by-nc/4.0/.

ORCID iD

Bin-Bin Chen http://orcid.org/0000-0002-1137-6965 


\section{REFERENCES}

1 Del Giudice M. An evolutionary life history framework for psychopathology. Psychol Inq 2014;25:261-300.

2 Del Giudice M. A tower unto heaven: toward an expanded framework for psychopathology. Psychol Inq 2014;25:394-413.

3 Del Giudice M. The evolutionary future of psychopathology. Current Opinion in Psychology 2016;7:44-50.

4 Hurst JE, Kavanagh PS. Life history strategies and psychopathology: the faster the life strategies, the more symptoms of psychopathology. Evolution and Human Behavior 2017;38:1-8.

5 Nesse RM. Evolutionary Psychology and Mental Health. In: The Handbook of evolutionary psychology. John Wiley \& Sons, Inc, 2015: 903-27.

6 Crawford C. Evolutionary psychology: counting babies or studying information-processing mechanisms. Ann N Y Acad Sci 2000;907:21-38.

7 Ellis BJ, Figueredo AJ, Brumbach BH, et al. Fundamental Dimensions of Environmental Risk : The Impact of Harsh versus Unpredictable Environments on the Evolution and Development of Life History Strategies. Hum Nat 2009;20:204-68.

8 Kaplan H, Gangestad S. Life history theory and evolutionary psychology. In: The Handbook of evolutionary psychology, 2005: 68-95.

9 Hill K. Life history theory and evolutionary anthropology. Evol Anthropol 1993;2:78-88.

10 Belsky J, Steinberg L, Draper P. Childhood experience, interpersonal development, and reproductive strategy: an evolutionary theory of socialization. Child Dev 1991;62:647-70.

11 Kaplan H, Hill K, Lancaster J, et al. A theory of human life history evolution: diet, intelligence, and longevity. Evol Anthropol 2000;9:156-85.

12 Figueredo A, Vásquez G, Brumbach B, et al. Consilience and life history theory: from genes to brain to reproductive strategy. Developmental Review 2006;26:243-75.

13 Baumard N. Psychological origins of the industrial revolution. Behav Brain Sci 2018:1-47.

14 Griskevicius V, Ackerman JM, Cantú SM, et al. When the economy falters, do people spend or save? responses to resource scarcity depend on childhood environments. Psychol Sci 2013;24:197-205.

15 Figueredo AJ, Vásquez G, Brumbach BH, et al. The K-factor: individual differences in life history strategy. Pers Individ Dif 2005;39:1349-60.

16 Del Giudice M, Gangestad SW, Kaplan HS. Life history theory and evolutionary psychology. In: The Handbook of evolutionary psychology: vol. 1. foundations. New York, NY: Wiley, 2015: 88-114.

17 Death CJS. Hope, And Sex - Life-History Theory And The Development Of ReproductiveE Strategies. Curr Anthropol 1993;34:1-24.

18 Chen B-B, Chang L. Procrastination as a fast life history strategy. Evol Psychol 2016;14:147470491663031.

19 Chen B-B, Qu W. Life history strategies and procrastination: the role of environmental unpredictability. Pers Individ Dif 2017;117:23-9.

20 Griskevicius V, Kenrick DT. Fundamental motives: how evolutionary needs influence consumer behavior. Journal of Consumer Psychology 2013;23:372-86.

21 Griskevicius V, Tybur JM, Delton AW, et al. The influence of mortality and socioeconomic status on risk and delayed rewards: a life history theory approach. J Pers Soc Psychol 2011;100:1015-26.

22 Strouts PH, Brase GL, Dillon HM. Personality and evolutionary strategies: the relationships between HEXACO traits, mate value, life history strategy, and sociosexuality. Pers Individ Dif 2017;115:128-32.

23 Belsky J, Schlomer GL, Ellis BJ. Beyond cumulative risk: distinguishing harshness and unpredictability as determinants of parenting and early life history strategy. Dev Psychol 2012;48:662-73.

24 Griskevicius V, Tybur JM, Ackerman JM, et al. The financial consequences of too many men: sex ratio effects on saving, borrowing, and spending. J Pers Soc Psychol 2012;102:69-80.

25 Simpson JA, Griskevicius V, Kuo SI-C, et al. Evolution, stress, and sensitive periods: the influence of unpredictability in early versus late childhood on sex and risky behavior. Dev Psychol 2012;48:674-86.

26 Belsky J, Pluess M, Widaman KF. Confirmatory and competitive evaluation of alternative gene-environment interaction hypotheses. J Child Psychol Psychiatr 2013;54:1135-43.

27 Belsky J, Pluess M. Beyond diathesis stress: differential susceptibility to environmental influences. Psychol Bull 2009;135:885-908.

28 Belsky J, Pluess $M$. The nature (and nurture?) of plasticity in early human development. Perspect Psychol Sci 2009;4:345-51.
29 Ellis BJ, Boyce WT, Belsky J, et al. Differential susceptibility to the environment: an evolutionary-neurodevelopmental theory. Dev Psychopathol 2011;23:7-28.

30 American Psychiatric Association. Diagnostic and statistical manual of mental disorders (DSM-5尺. American Psychiatric Publication; 2013.

31 Ende G, Cackowski S, Van Eijk J, et al. Impulsivity and aggression in female BPD and ADHD patients: association with ACC glutamate and GABA concentrations. Neuropsychopharmacology 2016:41:410-8.

32 Gomez R, Corr PJ. Adhd and personality: a meta-analytic review. Clin Psychol Rev 2014;34:376-88.

33 Frederick MJ. Birth weight predicts scores on the ADHD self-report scale and attitudes towards casual sex in college men: a short-term life history strategy? Evol Psychol 2012;10:147470491201000.

34 Russell AE, Ford T, Williams R, et al. The association between socioeconomic disadvantage and attention deficit/hyperactivity disorder (ADHD): a systematic review. Child Psychiatry Hum Dev 2016;47:440-58.

35 Martel MM, Goth-Owens T, Martinez-Torteya C, et al. A personcentered personality approach to heterogeneity in attentiondeficit/hyperactivity disorder (ADHD). J Abnorm Psychol 2010;119:186-96.

36 Lee H-J, Kwon S-M. Two different types of obsession: autogenous obsessions and reactive obsessions. Behav Res Ther 2003;41:11-29.

37 Lee H-J, Telch MJ. Differences in latent inhibition as a function of the autogenous-reactive OCD subtype. Behav Res Ther 2010;48:571-9.

38 Brüne M, O J, Schojai M, et al. Mating strategies and experience of early adversity in female patients with borderline personality disorder: insights from life history theory. Pers Individ Dif 2017;113:147-54

39 Brüne M. Life history theory as organizing principle of psychiatric disorders: implications and prospects exemplified by borderline personality disorder. Psychol Inq 2014;25:311-21.

40 Brüne M, Ghiassi V, Ribbert H. Does borderline personality disorder reflect the pathological extreme of an adaptive reproductive strategy? insights and hypotheses from evolutionary life-history theory. Clinical Neuropsychiatry: Journal of Treatment Evaluation 2010;7:3-9.

41 Krueger RF, Hicks BM, Patrick CJ, et al. Etiologic connections among substance dependence, antisocial behavior, and personality: modeling the externalizing spectrum 2009.

42 Armour S, Haynie DL. Adolescent sexual Debut and later delinquency. J Youth Adolesc 2007;36:141-52.

43 Lévesque M, Bigras M, Pauzé R. Externalizing problems and problematic sexual behaviors: same etiology? Aggress Behav 2010;36:358-70.

44 Negriff S, Susman EJ. Pubertal timing, depression, and externalizing problems: a framework, review, and examination of gender differences. Journal of Research on Adolescence 2011;21:717-46.

45 Caprara GV, Gerbino M, Perinelli E, et al. Individual differences in personality associated with aggressive behavior among adolescents referred for Externalizing behavior problems. J Psychopathol Behav Assess 2017;39:680-92.

46 Edwards RC, Hans SL. Infant risk factors associated with internalizing, externalizing, and co-occurring behavior problems in young children. Dev Psychol 2015;51:489-99.

47 Carneiro A, Dias P, Soares I. Risk factors for internalizing and Externalizing problems in the preschool years: systematic literature review based on the child behavior checklist 11/2-5. J Child Fam Stud 2016;25:2941-53.

48 Reyno SM, McGrath PJ. Predictors of parent training efficacy for child externalizing behavior problems--a meta-analytic review. $J$ Child Psychol Psychiatry 2006;47:99-111.

49 Westen D, Harnden-Fischer J. Personality profiles in eating disorders: rethinking the distinction between axis I and axis II. AJP 2001;158:547-62.

50 Tandon R, Keshavan MS, Nasrallah HA. . Schizophrenia, "Just the Facts" What we know in 2008. 2. Epidemiology and etiology. Schizophr Res 2008;102:1-18.

51 Shaner A, Miller G, Mintz J. Schizophrenia as one extreme of a sexually selected fitness indicator. Schizophr Res 2004;70:101-9.

52 Nettle D. Reconciling the mutation-selection balance model with the schizotypy-creativity connection. Behav Brain Sci 2006;29:418.

53 Del Giudice M, Angeleri R, Brizio A, et al. The evolution of autisticlike and schizotypal traits: a sexual selection hypothesis. Front Psychol 2010;1:41.

54 Kyaga S, Lichtenstein P, Boman M, et al. Creativity and mental disorder: family study of 300000 people with severe mental disorder. Br J Psychiatry 2011;199:373-9.

55 Nettle D, Clegg H, Schizotypy CH. Schizotypy, creativity and mating success in humans. Proc. R. Soc. B 2006;273:611-5. 
56 Del Giudice M, Klimczuk ACE, Traficonte DM, et al. Autistic-Like and schizotypal traits in a life history perspective: diametrical associations with impulsivity, sensation seeking, and sociosexual behavior. Evolution and Human Behavior 2014;35:415-24.

57 Beaussart ML, Kaufman SB, Kaufman JC. Creative activity, personality, mental illness, and short-term mating success. J Creat Behav 2012;46:151-67.

58 Mating DGM. Sexual selection, and the evolution of schizophrenia. World psychiatry 2017;16:141-2.

59 Nederlof AF, Muris P, Hovens JE. Psychotic-like experiences and aggressive behavior in a non-clinical sample. Pers Individ Dif 2012:53:33-7.

60 Burns JK. An evolutionary theory of schizophrenia: cortical connectivity, metarepresentation, and the social brain. Behav Brain Sci 2004;27:831-55.

61 Opler M, Charap J, Greig A, et al. Environmental risk factors and schizophrenia. Int J Ment Health 2013;42:23-32.

62 Yeo RA, Pommy J, Padilla EA. Strategic choices versus Maladapative development. Psychol Inq 2014;25:389-93.

63 Hesselbrock VM, Hesselbrock MN. Are there empirically supported and clinically useful subtypes of alcohol dependence? Addiction 2006;101:97-103.

64 Mangerud WL, Bjerkeset O, Holmen TL, et al. Smoking, alcohol consumption, and drug use among adolescents with psychiatric disorders compared with a population based sample. J Adolesc 2014;37:1189-99.

65 Bejerot S, Eriksson JM. Sexuality and gender role in autism spectrum disorder: a case control study. PLoS One 2014;9:e87961.

66 Whitehouse AJO, Maybery MT, Hickey M, et al. Brief report: autisticlike traits in childhood predict later age at menarche in girls. $J$ Autism Dev Disord 2011:41:1125-30.

67 Byars SG, Boomsma JJ. Opposite differential risks for autism and schizophrenia based on maternal age, paternal age, and parental age differences. Evol Med Public Health 2016;2016:286-98.

68 Schwartzman BC, Wood JJ, Kapp SK. Can the five factor model of personality account for the variability of autism symptom expression? multivariate approaches to behavioral phenotyping in adult autism spectrum disorder. J Autism Dev Disord 2016:46:253-72.

69 Lodi-Smith J, Rodgers JD, Cunningham SA, et al. Meta-Analysis of big five personality traits in autism spectrum disorder. Autism 2019:23:556-65.

70 Antshel KM, Zhang-James Y, Wagner KE, et al. An update on the comorbidity of ADHD and ASD: a focus on clinical management. Expert Rev Neurother 2016:16:279-93.

71 Kotov R, Gamez W, Schmidt F, et al. Linking "big" personality traits to anxiety, depressive, and substance use disorders: A meta-analysis. Psychol Bull 2010;136:768-821.

72 Dussault F, Brendgen M, Vitaro F, et al. Longitudinal links between impulsivity, gambling problems and depressive symptoms: a transactional model from adolescence to early adulthood. $J$ Child Psychol Psychiatry 2011;52:130-8.

73 Gjerde PF. Alternative pathways to chronic depressive symptoms in young adults: gender differences in developmental trajectories. Child Dev 1995;66:1277-300.

74 Miech RA, Shanahan MJ. Socioeconomic status and depression over the life course. $J$ Health Soc Behav 2000;41:162-76.

75 Kaltiala-Heino R, Kosunen E, Rimpelä M. Pubertal timing, sexual behaviour and self-reported depression in middle adolescence. $J$ Adolesc 2003;26:531-45.

76 Bakermans-Kranenburg MJ, van IJzendoorn MH. The first 10,000 adult attachment interviews: distributions of adult attachment representations in clinical and non-clinical groups. Attach Hum Dev 2009;11:223-63.
77 Hertler SC. The biology of obsessive-compulsive personality disorder symptomatology: identifying an extremely K-selected life history variant. Evolutionary Psychological Science 2016;2:1-15.

78 Kotov R, Krueger RF, Watson D, et al. The hierarchical taxonomy of psychopathology (HiTOP): a dimensional alternative to traditional nosologies. J Abnorm Psychol 2017;126:454-77.

79 Chmielewski M, Clark LA, Bagby RM, et al. Method matters: understanding diagnostic reliability in DSM-IV and DSM-5. J Abnorm Psychol 2015;124:764-9.

80 Lahey BB, Rathouz PJ, Van Hulle C, et al. Testing structural models of DSM-IV symptoms of common forms of child and adolescent psychopathology. J Abnorm Child Psychol 2008;36:187-206.

81 Lahey BB, Zald DH, Perkins SF, et al. Measuring the hierarchical General factor model of psychopathology in young adults. Int $J$ Methods Psychiatr Res 2018:27:e1593.

82 Widiger TA, Sellbom M, Chmielewski M, et al. Personality in a hierarchical model of psychopathology. Clin Psychol Sci 2019;7:77-92.

83 Caspi A, Moffitt TE. All for one and one for all: mental disorders in one dimension. Am J Psychiatry 2018;175:831-44.

84 Chang L, Lu HJ, Lansford JE, et al. Environmental harshness and unpredictability, life history, and social and academic behavior of adolescents in nine countries. Dev Psychol 2019;55:890-903.

85 Kogan SM, Cho J, Simons LG, et al. Pubertal timing and sexual risk behaviors among rural African American male youth: testing a model based on life history theory. Arch Sex Behav 2015;44:609-18.

86 Mittal C, Griskevicius V. Sense of control under uncertainty depends on people's childhood environment: A life history theory approach. $J$ Pers Soc Psychol 2014;107:621-37.

87 Del Giudice M. The life history model of psychopathology explains the structure of psychiatric disorders and the emergence of the $P$ factor. Clin Psychol Sci 2016;4:299-311.

88 Schmitt DP. Sociosexuality from Argentina to Zimbabwe: a 48-nation study of sex, culture, and strategies of human mating. Behav Brain Sci 2005;28:247-75.

89 Korver-Nieberg N, Berry K, Meijer C, et al. Associations between attachment and psychopathology dimensions in a large sample of patients with psychosis. Psychiatry Res 2015;228:83-8.

90 Levy KN, Johnson BN, Clouthier TL, et al. An attachment theoretical framework for personality disorders. Canadian Psychology/ Psychologie canadienne 2015;56:197-207.

91 Mikulincer M, Shaver PR. An attachment perspective on psychopathology. World Psychiatry 2012;11:11-15.

92 Del Giudice M, Sex DGM. Sex, attachment, and the development of reproductive strategies. Behav Brain Sci 2009;32:1-21.

93 Chen B-B. Insecure attachment, resource control, and unrestricted sociosexuality: from a life history perspective. Pers Individ Dif 2017:105:213-7.

94 Chisholm JS. The evolutionary ecology of attachment organization. Hum Nat 1996;7:1-37.

95 Pluess M, Belsky J. Vantage sensitivity: individual differences in response to positive experiences. Psychol Bull 2013;139:901-16.

96 Saleh A, Potter GG, McQuoid DR, et al. Effects of early life stress on depression, cognitive performance and brain morphology. Psychol Med 2017;47:171-81.

97 Gardner KL, Hale MW, Lightman SL, et al. Adverse early life experience and social stress during adulthood interact to increase serotonin transporter mRNA expression. Brain Res 2009;1305:47-63.

98 Bravo JA, Dinan TG, Cryan JF. Early-Life stress induces persistent alterations in 5-HT1A receptor and serotonin transporter mRNA expression in the adult rat brain. Front Mol Neurosci 2014;7:24

99 Sachs BD, Rodriguiz RM, Tran HL, et al. Serotonin deficiency alters susceptibility to the long-term consequences of adverse early life experience. Psychoneuroendocrinology 2015;53:69-81.

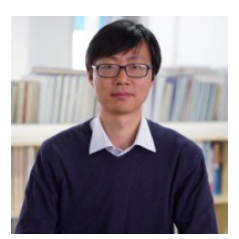

Binbin Chen obtained his Ph.D. degree from the Chinese University of Hong Kong, Hongkong, China, in 2012. Now, he is an Associate Professor and the Department Chairman of the Department of Psychology at Fudan University in Shanghai, China. Currently, he is a committee member on the Behavioral and Health Division of the Chinese Psychological Society and the Chinese Prevention Medicine Association. His main research interests include behavioral health and developmental psychopathology. 